\title{
Caracterização do terraço de abrasão da falésia da Baronesa e sua utilização na cidade de Alcântara - MA
}

\author{
Characterization of abrasion terrace of Baronesa cliff is its use in the city of Alcântara - MA \\ Silva $^{1}$, C. H. S.; Lima ${ }^{2}$ I. M. M. F. \\ Carlos-henriquess@hotmail.com
}

\begin{abstract}
Resumo
O presente trabalho faz um estudo a respeito do terraço de abrasão da falésia da Baronesa e sua utilização na cidade de Alcântara, Maranhão. A zona costeira do município é caracterizada pela presença de um conjunto singular de terraços de abrasão que são feições geomorfológicas desgastadas pelos agentes oceanográficos, sendo constituídos por diversos materiais. $\mathrm{Na}$ área de estudo o terraço de abrasão é formado por material solto, constituído por arenitos ferruginosos e dolomitos, sendo o clima, a geologia e os agentes oceanográficos os principais responsáveis por sua morfogênese e morfodinâmica. Sua constituição geológica está relacionada à Formação Barreiras e ao Membro Alcântara da Formação Itapecuru. O objetivo deste trabalho foi o de apresentar uma caracterização sobre essa feição e identificar sua exploração e uso na cidade de Alcântara. Para a realização desta pesquisa utilizou-se a revisão da literatura, trabalho de campo para a observação in situ da feição, aplicação de ficha de campo e entrevistas com pescadores. Os terraços de abrasão são feições geomorfológicas de grande importância, pois são balizadores de amplas pesquisas, desde evidências de oscilações do nível do mar até planejamento turístico e inter-relação com outras feições geomorfológicas presentes na zona costeira.
\end{abstract}

Palavras-chave: Terraço de abrasão. Alcântara. Zona costeira.

\begin{abstract}
The present work is a study about the cliff abrasion terrace of Baronesa and their use in the city of Alcântara, Maranhão. The coastal area of the municipality is characterized by the presence of a singular set abrasion terraces that are geomorphological features worn by oceanographic agents, being made of different materials. In the study area the abrasion terrace is made up of loose material consisting of sandstones and ferruginous dolomites, and the climate, geology and oceanography agents primarily responsible for their morphogenesis and morphodynamics. Its geological formation is related to the Formação Barreiras and the Membro Alcântara of Formação Itapecuru. The aim of this paper is to present a characterization of this feature, and as this was and is being explored in the town of Alcântara. For this research we used the literature review, fieldwork to observe in situ of the feature field form of application and interviews with fishermen. The abrasion terraces are geomorphological features of great importance, as are benchmarks of extensive research provided evidence of sea level fluctuations to tourism planning and interrelation with other geomorphological features present in the coastal zone.
\end{abstract}

Keywords: Abrasion terrace. Alcântara. Coastal zone.

\section{INTRODUÇÃO}

O processo de uso e ocupação da zona costeira vem se tornando preocupante, por não existir um planejamento de ocupação e exploração adequados destas áreas. Assim, há uma facilidade de sua ocupação e antropização, tendendo a ocorrer altos índices de urbanização, o que acarreta problemas tanto para o ser humano, quanto para os ambientes.

A variedade de feições geológicas e geomorfológicas dos ambientes costeiros reflete seu dinamismo e suas relações com o meio. Assim, conhecer a costa é contribuir de forma significativa para ocupação, uso e conservação de seus recursos. 
No decorrer da história humana, as populações se estabeleceram preferencialmente próximo a áreas fluviais e costeiras, demonstrando que essas eram, e continuam sendo, lugares de atração (MORAES, 2007).

A zona costeira brasileira constitui-se em uma parcela privilegiada quanto aos recursos naturais, econômicos e humanos, configurando-se como patrimônio nacional. Os ecossistemas dessa zona resultam da interação de ambientes marinhos e terrestres caracterizados por recortes, pela diversidade biológica e fragilidade ambiental, sofrendo influência tanto de processos naturais quanto antrópicos (STROHAECKER, 2008).

A zona costeira do Maranhão possui extensão aproximada de $640 \mathrm{~km}$, estendendo-se no sentido Oeste-Leste da foz do Rio Gurupi, na divisa com o Estado do Pará, até o delta do Rio Parnaíba, no limite com o Estado do Piauí, sendo a segunda mais extensa do Brasil e da Região Nordeste. Apresenta largura variável de Oeste para Leste, sendo mais ampla na área das reentrâncias. Por apresentar características geoambientais diferenciadas, encontra-se subdividida em Costa Ocidental, Golfão Maranhense e Costa Oriental.

A dinâmica da paisagem na área do Golfão Maranhense, onde se encontra a área de estudo, é facilitada pela fragilidade das estruturas geológicas, por sua exposição aos agentes modeladores do relevo como os de origem climática, hidrológica e oceanográfica. Pela intensa atividade eólica, marinha e fluviomarinha, gerando ondas e correntes que modelam o maior conjunto de falésias da costa do Maranhão. Já a proximidade do Equador e a configuração do relevo favorecem a grandes amplitudes das marés (FEITOSA; TROVÃO, 2006).

$\mathrm{Na}$ área do Golfão Maranhense encontra-se o município de Alcântara, que apresenta diversificadas feições geomorfológicas, destacando-se as planície de maré, dunas fixas e móveis, paleodunas, tabuleiros, vertentes, praias, falésias e terraços de abrasão. Estes, segundo Guerra e Guerra (2001), formam uma superfície desgastada pelas ondas do mar que vai se ampliando à medida que a falésia recua.

Segundo Christofoletti (1980), o terraço de abrasão é proveniente de ação erosiva, num processo combinado de desgaste da falésia e deposição dos materiais na sua base, os quais são retrabalhados pela ação marinha para construir o terraço de construção marinha. Decorrente da ação da onda que escava a base da falésia, formando caneluras - pequenos sulcos ou regos que cortam as rochas, geralmente no sentido do declive da encosta, depositando os detritos no terraço de abrasão, numa primeira fase, sendo depois os materiais arrastados para construir o terraço de construção marinha. Assim, o forte e contínuo trabalho das ondas sobre a falésia leva ao seu desgaste e colapso, resultando no seu recuo. 
Tendo em vista que pesquisas referentes a terraços de abrasão e sua classificação são escassas no Estado do Maranhão, com destaque para o trabalho de Silva (2015), buscou-se nesta pesquisa ampliar esse conhecimento através da caracterização do terraço de abrasão da falésia da Baronesa e de sua exploração e utilização em ruas e praças na cidade de Alcântara.

\section{METODOLOGIA}

Para a realização desta pesquisa utilizou-se a abordagem sistêmica, já que o relevo é concebido como resultante da atuação simultânea de processos endógenos e exógenos. O pensamento sistêmico empregado nos estudos geográficos tem em vista interpretar a complexidade de um sistema espacial segundo as interações que se processam entre os atributos formadores e que lhes confere caráter dinâmico e não linear.

Para o alcance dos objetivos propostos, o trabalho se iniciou pelo levantamento do material bibliográfico, seguido da realização de trabalhos de campo como suporte à organização dos dados e sua análise final. O levantamento da bibliografia foi realizado nas bibliotecas centrais da Universidade Estadual do Maranhão (UEMA), da Universidade Federal do Maranhão (UFMA) e da Universidade Federal do Piauí (UFPI); em anais de eventos, site, artigos, obras e documentos com dados referentes à especificidade do tema em questão.

Os trabalhos de campo foram realizados objetivando o reconhecimento da feição e análise visual dos aspectos morfológicos, geológicos, sedimentológicos, dinâmica costeira, cores, textura e registro através de fotografias. Nessas ocasiões foram aplicadas fichas de campo, sob a forma de um "questionário" a respeito da feição geomorfológica, com o intuito de padronizar e organizar as informações coletadas.

Foram realizadas, ainda, entrevistas com pescadores locais a respeito da falésia, do terraço de abrasão da Baronesa e sobre a cidade de Alcântara, buscando identificar aspectos relativos à intensidade dos processos morfodinâmicos atuais da área, principalmente a partir da exploração do terraço para pavimentação da cidade. Não foi possível, no entanto, realizar entrevistas com representantes da prefeitura municipal para identificar aspectos da gestão desse espaço.

\section{RESULTADOS E DISCUSSÃO}

\section{Caracterização da área de estudo}


A falésia e o terraço de abrasão da Baronesa estão localizados ao Sul da cidade de Alcântara, na porção Leste do município, especificamente na Microrregião Geográfica do Litoral Ocidental Maranhense. O ponto central dessa área de estudo corresponde as seguintes coordenadas geográficas: -2²4'10” e -44²4'54” (Figura 1).

O território que atualmente pertence a Alcântara era, em 1612, um aglomerado de aldeias com o nome de Tapuitapera. Com as constantes incursões de franceses nessa área indígena, estabeleceram-se relações amistosas entre esses povos. No entanto, após a expulsão dos franceses, firmou-se o domínio português a partir de 1616, mas a importância da aldeia não foi diminuída pois, com a subdivisão das capitanias do Maranhão e do Grão-Pará, Tapuitapera passou à condição de líder da capitania de Cumã, tendo se tornado vila em março de 1648, com o nome de Alcântara, sob a invocação de São Matias. A partir de então Alcântara prosperou progressivamente em todos os setores e tornou-se o maior centro produtor da Província, tendo sido elevada à categoria de cidade em 1836, fase em que atingiu o apogeu de sua grandeza. Gradativamente, porém, esta perde o primado na produção maranhense, refletindo o declínio das atividades econômicas em sua vida social. Em 22 de dezembro de 1948, data do tricentenário de sua elevação à vila, Alcântara foi considerada "Cidade Monumento Nacional" (IBGE, 1959), contando recentemente com uma população de 21.851 habitantes, sendo apenas 6.399 sua população urbana (IBGE, 2010).

A zona costeira de Alcântara apresenta suas feições morfológicas modeladas por diversos agentes oceanográficos (marés, ondas e correntes litorâneas), como decorrência principalmente de sua proximidade do Equador e influência do Oceano Atlântico. Os ventos alísios, que sopram de NE, são um dos grandes responsáveis pela dinâmica costeira e possuem um papel importante na desagregação e transporte de sedimentos. Outro fator importante é o clima, que na área de estudo apresenta características diferenciadas em dois períodos distintos: o primeiro semestre do ano é caracterizado por ser chuvoso, com índices pluviométricos superior a $2.000 \mathrm{~mm}$ anuais, enquanto o segundo é de estiagem com temperaturas medias anuais superiores a $27^{\circ}$ (UEMA, 2002). 


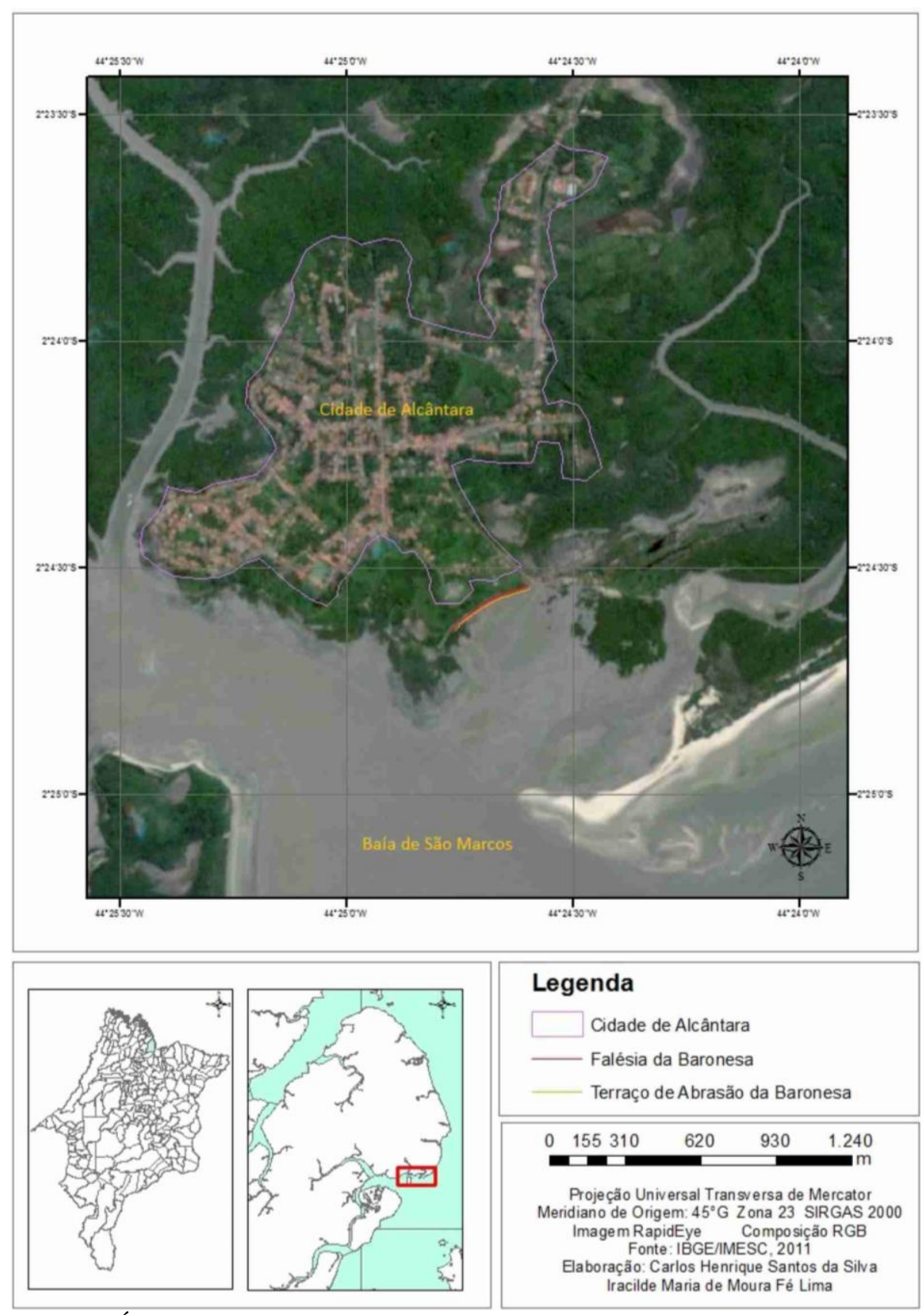

Figura 1. Área de estudo. Base de dados: IBGE/IMESC, 2011. Org. dos autores, 2016.

As marés da área de estudo se caracterizam por uma hidrodinâmica regida pelo sistema de marés semi-diurnas (duas preamares e duas baixa-mares por dia lunar com intervalos proporcionais de cerca de $6 \mathrm{~h}$ ), com amplitude média de 4,6m, podendo atingir 7,2m quando das grandes sizígias, sendo essa amplitude a responsável por profundas modificações no processo de sedimentação e erosão da costa. As ondas geradas pelos ventos são importantes agentes de energia, pois provocam erosão e deposição, através da remobilização de areia para diversas áreas do sistema praial. As correntes litorâneas, dependendo do ângulo de incidência, conseguem transportar grandes quantidades de sedimentos e colocá-los em movimento pela ação das ondas, fazendo com que eles 
se desloquem por longas distâncias. Esses agentes exercem grande influência na dinâmica costeira e são responsáveis pela modelado e configuração das feições morfológica.

A geologia é outro fator condicionante para a susceptibilidade que a zona costeira apresenta para os processos de sedimentação e erosão. Litoestratigraficamente, essa área é caracterizada por três unidades principais: Formação Itapecuru (Cretáceo-Superior), Formação Barreiras (Paleógeno/Neógeno) e Formação Açuí (Pleistoceno/ Holoceno), conforme Rodrigues et al (1994).

No Membro Alcântara da Formação Itapecuru tem-se a presença de siltitos e folhelhos vermelhos, coesos, de estratificação plano-paralela, disposta de forma tabular em camadas decimétricas, que intercalam alguns bancos lenticulares de calcário creme esbranquiçados. Repousa em discordância angular sobre os sedimentos do Membro Psamítico.

A Formação Barreiras repousa sobre a Formação Itapecuru, caracterizando-se por apresentar sedimentos areno-argilosos e ocasionalmente conglomeráticos de coloração róseoavermelhados, ferruginizados, parcialmente consolidados. Apresenta-se laterizado com perfil pouco evoluído ou imaturo e os níveis mais arenosos estão ferruginizados, mostrando coloração avermelhada a amarelada ocre, sendo que os intervalos argilosos encontram-se, no geral, caulinizados com uma coloração esbranquiçada a rósea.

A Formação Açuí compõe-se de sedimentos arenosos inconsolidados e argilosos nãoadensados que preenchem as partes topograficamente mais baixas e de areias de praias e de dunas móveis da faixa costeira atual.

Destaque-se que a área costeira da cidade de Alcântara no decorrer da sua colonização foi amplamente modificada principalmente pela ação antrópica, inicialmente pela construção de seus portos e posteriormente pela retirada de materiais do terraço de abrasão da falésia da Baronesa para pavimentação da cidade.

\section{Caracterização do Terraço de Abrasão da Baronesa}

O terraço de abrasão da Baronesa, formado pela dissecação da falésia de mesmo nome, é constituído principalmente por material solto, formado por arenitos ferruginosos, também chamados de arenitos de praia ou beach rocks, e por dolomitos que afloram na área ou que despencam da face da falésia (Figura 2). 


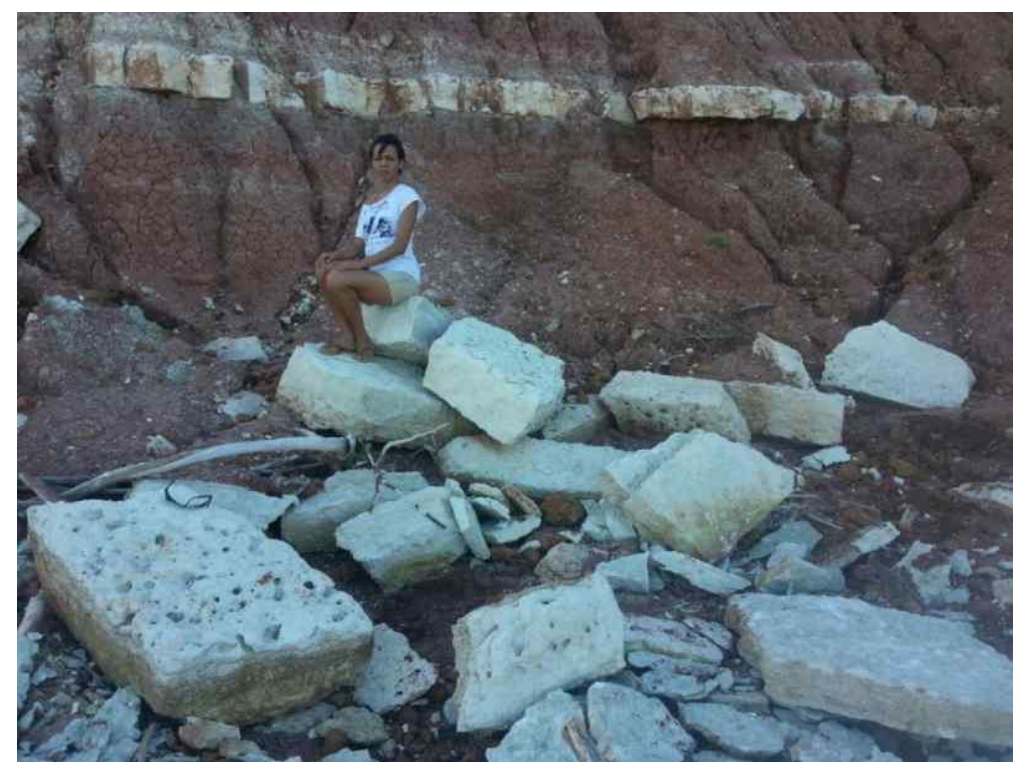

Figura 2. Dolomitos que formam o terraço de abrasão da falésia da Baronesa. Fonte: os autores, 2015

O arenito ferruginoso que compõe o terraço de abrasão na área de estudo é originário principalmente da stone line localizada no topo da falésia, apresentando tamanhos diferenciados, variando de $22 \times 22 \mathrm{~cm}$, mas com predomínio de $5 \mathrm{~cm}$. O processo de formação desses arenitos se dá no interior do solo, através do processo de laterização, verificando-se uma hidratação e oxidação dos elementos minerais, sendo o ferro liberado sob a forma de hidróxido férrico. Dessa forma, estes se encontram consolidados no interior do solo, sendo expostos pela erosão superficial e acabam rolando e depositados na base da falésia para formar o terraço de abrasão. Estes, posteriormente, são modelados pelos agentes oceanográficos (SILVA, 2015).

Observou-se, ainda, que quedas e afloramentos de dolomitos são comuns formando um terraço de abrasão com blocos inicialmente quadrados com $77 \times 56 \mathrm{~cm}$, de coloração creme a acinzentada. Posteriormente, estes são modelados pelos agentes oceanográficos tornando-os mais arredondados e cimentados, com pequenas cavidades encontradas em sua face. Estes também se fragmentam assemelhando-se a um tabuleiro de xadrez, apresentando espessura do material mais reduzida, com predominância de 30x50cm.

Outro aspecto observado se refere à quedas dos blocos de dolomitos, pois estas são influenciados pela face inclinada da falésia, tendo, portanto, maior susceptibilidade a lavagem pela água das chuvas que desencadeia processos erosivos de maior intensidade. No período chuvoso o fluxo de água que escorre pelas incisões da ravina se torna decisivo para o corte do dolomito em sentido vertical.

\section{Utilização do terraço de abrasão na pavimentação de ruas na cidade de Alcântara}


Através das observações de campo e entrevistas com moradores locais foi constatado que o terraço de abrasão da falésia da Baronesa foi intensamente utilizado para a pavimentação de ruas, calçadas e praças da cidade pela prefeitura municipal, durante o fim da década de 90 e início dos anos 2000, principalmente por este se localizar muito próximo a cidade e possuir material abundante para a pavimentação. Destaque-se que até o ano de 1959 apenas $10 \%$ das ruas da sede de Alcântara eram calçadas com paralelepípedos, $20 \%$ com pedra comum ou irregular e o restante (70\%) sem calçamento (IBGE, 1959).

Identificou-se que do terraço de abrasão foram retirados dois tipos principais de pedra para a pavimentação da cidade. O primeiro constituído por arenitos ferruginosos, ou lateritas, de cor preta, irregulares e rugosas e que, por apresentarem a cor preta e serem transportados na cabeça dos escravos, passaram a ser chamados de "pedra cabeça de negro".

O segundo tipo é constituído por dolomitos de cor creme a acinzentada, conhecido localmente como pedra de cantaria, também chamada de pedra de jacaré. A cantaria é um conjunto de pedras utilizadas em construções antigas, lavradas e esquadrejadas segundo técnicas minuciosas. Existem outras versões para a origem desse termo, como o que decorre do fato de que, quando eram trazidas nos lastros dos navios no Brasil colonial, estas serviam para equilibrar os navios, dandolhes maior estabilidade, pois, com o balançar do navio, os blocos se atritavam produzindo um som como se fosse um canto. Uma outra versão relata que os escravos cantavam ao talhar e modelar esses blocos. Destaque-se que a dolomita se fragmenta de forma retangular, sendo polida ao longo do tempo, e também é muito usada nas soleiras das portas das casas coloniais.

Utilizando esses materiais, as ruas de Alcântara são uma atração à parte. Revestidas com arenitos ferruginosos e dolomitos, formam losangos em preto e branco, contrastando com os casarões coloniais, ao mesmo tempo em que trazem um charme e bucolismo próprios desse lugar (Figura 3).

Mais recentemente a prefeitura municipal proibiu a retirada de materiais desse terraço de abrasão para pavimentação ou outros fins, conforme informações de moradores locais. Essa medida foi atribuída ao fato do forte de São Sebastião, construído em 1763 no topo da falésia da Baronesa, encontrar-se sob risco de desmoronamento. Com relação aos aspectos jurídicos dessa medida não se localizou nenhum documento como decretos ou leis que legalizassem tal ato.

No entanto, constatou-se que retirada de materiais da base da falésia, principalmente dolomitos, por alguns moradores da cidade, ainda vem ocorrendo de forma moderada para uso ornamental em residências, sendo utilizado como piso, ou como batentes de portas e janelas; bem 
como a própria prefeitura municipal, que continua utilizando esses materiais, em menor quantidade, para pavimentar ruas da cidade de Alcântara.

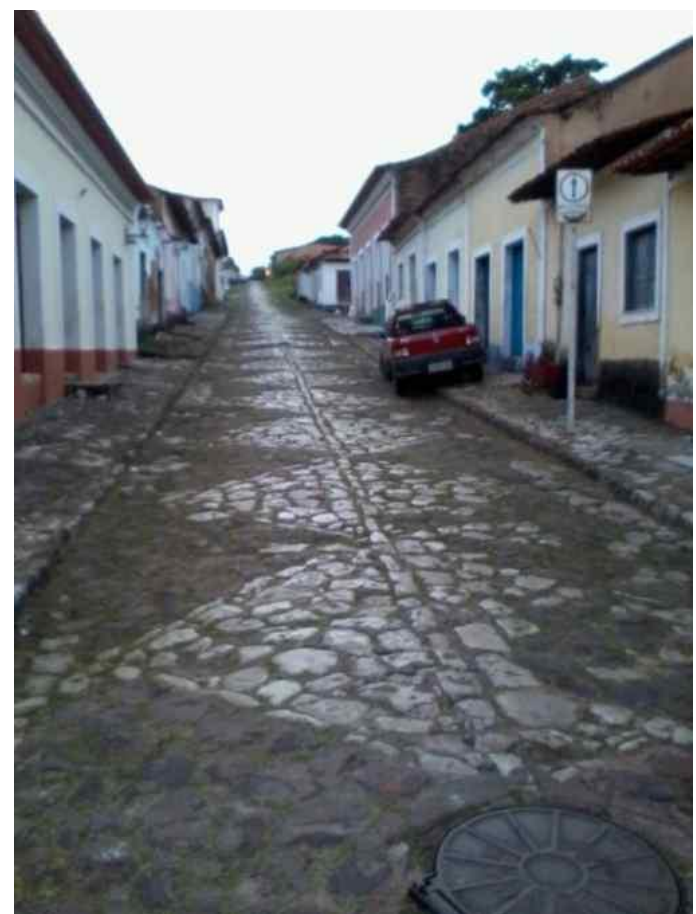

Figura 3. Ladeira do Jacaré, rua revestida de arenitos ferruginosos e dolomitos. Fonte: os autores, 2015

\section{CONSIDERAÇÕES FINAIS}

Os terraços de abrasão atuam como uma importante proteção natural, contribuindo para a dissipação da energia das ondas incidentes na costa, além disso, são indicadores de paleolitorais, evidenciando fases de estabilidade do nível do mar. Com relação à sua dinâmica, observou-se que os processos erosivos costeiros, cujos ritmos encontram-se associados predominantemente ao clima e à dinâmica marinha, correspondem aos principais agentes responsáveis pela formação e modelagem dos terraços de abrasão em Alcântara.

Esses processos ocorrem a partir do escoamento superficial na face das falésias gerado pelas intensas precipitações pluviométricas no período chuvoso, de janeiro a junho, causando incisões na face da falésia sob a forma de sulcos e por vezes de ravinas, acarretando o afloramento de lateritas (ou cangas). Estes processos, associados à ação das ondas de marés fazem aflorar e deixar os materiais expostos ao intemperismo, facilitando o seu tombamento e a alimentação do terraço de abrasão.

A exploração inadequada dos terraços de abrasão para retirada de materiais foi muito intensa em Alcântara e, mesmo estando atualmente com exploração moderada, permanece sem leis 
ou quaisquer meios que garantam a sustentabilidade da área, tornando-se necessário que os órgãos responsáveis sejam enérgicos e mais comprometidos com as causas ambientais.

Este trabalho permitiu perceber-se que os estudos dos terraços de abrasão são de grande importância para o planejamento da exploração e também de conservação das faixas litorâneas maranhenses, além de servirem de subsídio para amplas pesquisas, desde evidências de oscilações do nível do mar, planejamento turístico e inter-relações com as demais geoformas, como o tabuleiro costeiro, praias e falésias.

\section{REFERÊNCIAS}

CHISTOFOLETTI, A. Geomorfologia. São Paulo: Edgar Blücher, 2a edição,1980. 198 p.

FEITOSA, A. C.; TROVÃO, J. R. Atlas do Maranhão: espaço geo-histórico e cultural. João Pessoa-PB: Grafset, 2006. 207 p.

GUERRA, A. T.; GUERRA, A. J. T. Novo dicionário geológico-geomorfológico. 2a ed. Rio de Janeiro: Bertrand Brasil, 2001. 648 p.

INSTITUTO BRASILEIRO DE GEOGRAFIA E ESTATÍSTICA. Enciclopédia dos municípios brasileiros. Rio de Janeiro, 1959. V. 15. 660 p.

Censo Demográfico 2010. Disponível em:

http://www.censo2010.ibge.gov.br/sinopse/index.php?uf=21\&dados=1. Acesso em: 20/07/2016.

MORAES, A. C. R. Contribuição para a gestão da zona costeira do Brasil: elementos para uma geografia do litoral brasileiro. São Paulo: Annablume, 2007. 232 p.

RODRIGUES, T. L. N.; ARAÚJO, C.C.; CAMAZZATO, E.; RAMGRAB, G.E. (Orgs.). São Luís, Folha SA-23-2-A, Cururupu, Folha SA-23-X-C, escala 1: 1.000.000. Brasília: Companhia de Pesquisa de Recursos Minerais, Programa Levantamentos Geológicos Básicos do Brasil, 1994. 185 p.

SILVA, C. H. S. Análise de terraços de abrasão na ilha do Medo, São Luís - MA. In: XVI SIMPÓSIO BRASILEIRO DE GEOGRAFIA FÍSICA APLICADA, 5., 2015, Teresina-PI. Anais... Teresina: UFPI, 2015. 2782-2788 p.

STROHAECKER, T.M. Dinâmica populacional. In ZAMBONI, A e NICOLADI, J.L. (orgs).

Macrodiagnóstico da Zona costeira e marinha do Brasil. Brasília: MMA, 2008. 59-73 p.

UEMA - Gerencia de Planejamento e Desenvolvimento Econômico, Laboratório de

Geoprocessamento. Atlas do Maranhão. São Luís: GEPLAN, 2002. 44 p.

Recebido em: 14/08/2016

Aceito para publicação em: 01/10/2016 